\title{
PQA - THE SUCCESS FACTOR TO REACH NEXT PERFORMANCE LEVEL IN HOT AND COLD ROLLING *
}

Jens Kempken ${ }^{1}$

T. Hüper ${ }^{2}$

\begin{abstract}
A competitive landscape pressurizes the steel producers business, zero defect requirements from customers forces the operators for additional efforts in process control and quality management. The so called quality related cost, which include also rework, cost for downgrading or even scabbing of material is already a remarkable lever in a plants profitability breakdown. The introduction of advanced state of the art grades in the product portfolio requires already a budgeting for the expenses for R\&D and quality management. PQA has been developed as a process and quality management software solution next to existing level 2 or level 3 automation systems. It is focusing on the analysis of process data, equipment information, in line quality measurement devices and trend analysis to obtain an answer whether the process is according to definition and expectation and whether the intermediate or final product can be shipped for further processing as prime material. Advanced analytics which are linked to an expert know how based configuration identifies deficiencies in the production and processing process. An intelligent, state of the art quality rating system evaluates tolerable deviations. PQA comprises the software platform including the database, data configurator and collector from the different sources in the production process and units. The core element of the platform is the knowledge based expert know how package defining process and quality determining fundamentals. The paper describes the structure of the software package, it gives insights on the expert know how package, process and quality evaluation and points out the customer benefits, cost reduction, improvement yield, customer satisfaction increase. The link to recent operational references is given.
\end{abstract}

Keywords: Process; Product; Performance; Optimization; Quality management; Expert know how; Automation; Digitization; Quality assessment; Quality management; AHSS multiphase steel grades.

1 Dr. Ing. , SMS group GmbH - MET/Con Metallurgical Plant \& Process GmbH_40239 Düsseldorf, Germany.

2 SMS group GmbH - MET/Con Metallurgical Plant \& Process GmbH_40239 Düsseldorf, Germany. 


\section{INTRODUCTION}

A competitive landscape pressurizes the steel producers business, zero defect requirements from customers forces the operators for additional efforts in process control and quality management. Especially from the automotive sector, the supply of $100 \%$ prime quality has become essential and this supply need to be on time. The related quality costs and the yield of first class products define very much the steel companies' profitability and overall success significantly. The introduction of advanced state of the art grades in the product portfolio requires already a budgeting for the expenses for R\&D and quality management.

The SMS group together with its subsidiary MET/Con has developed a comprehensive solution to assess the product quality over the production and processing chain. Process and production parameters originating from various data sources of the process automation are examined on their impact of quality related characteristics.

Expert know how and comprehensive operational experience is translated into a quality guideline and a regulation framework as the sensitive core of the PQA solution.

Once implemented, the system identifies immediately steel grade specific, deviations from ideal standard and proposes corrective actions including a final evaluation for each product at each processing step.

The PQA (Product Quality Analyser and Advisor) system is a substantial tool for root cause quality analysis and provides the required support to the production team. It will become an integral part of the corporate quality management system.

\section{MOTIVATION}

Global competition forces the steel companies to satisfy their customers with state of the art steel grades, premium product quality, and timely delivery taking competitive pricing into consideration. The remaining margin depends very much on the premium a supplier can realize for special/premium products and services providing additional value to the customer.

Taking into consideration that the value contribution from scrap/raw material basket (iron ore, coal) to processed galvanized steel is around $100 \%$ (figure 1), it is obvious that the identification of deficiencies in the process, which will or can lead to quality constraints becomes more and more important. The earlier a critical deviation can be observed the better countermeasures can be executed in the following processes.

In this regard the PQA system is supporting the idea of dynamic processing by considering qualitative short comings of the material in earlier processing stages by correcting them in later process steps, if considered to be feasible. This decision will be made by the PQA software based on its inherent experience and metallurgical, operational and qualitative know how. 


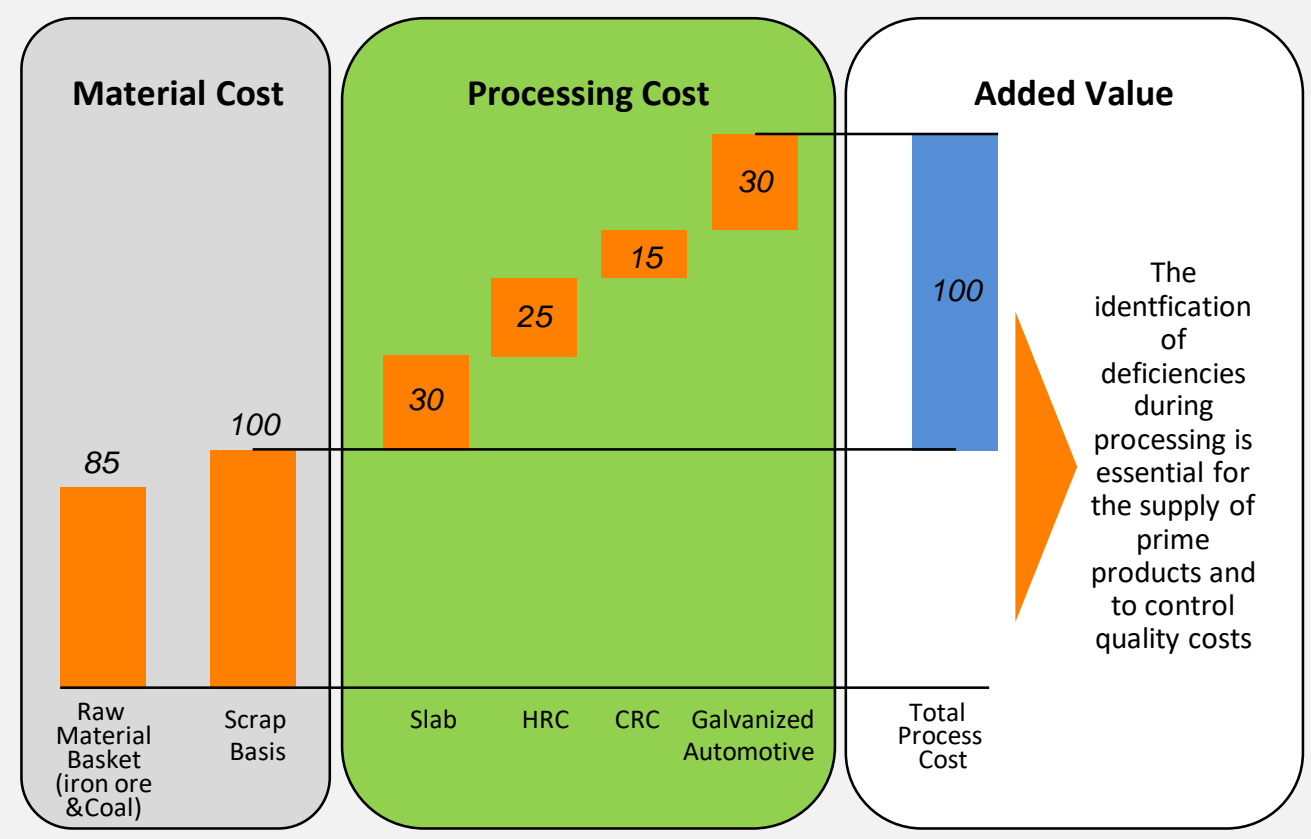

Example: Automotive DP Grade, Index based on 1t scrap

Figure 1: Value Contribution in Steelmaking

\section{OBJECTIVES OF PLANT WIDE PRODUCT QUALITY SYSTEM}

Driven by market developments towards increasing demand for high end products in new market segments for advanced applications (surface quality and mechanical properties) customers are requiring for a holistic integrated support in quality optimization and management. MET/Con, a subsidiary of the SMS group, developed and engineered a plant wide product quality assessment system.

The main purpose of the PQA is a quality decision support: is the material, intermediate product suitable for further processing or supply?

\begin{tabular}{|c|c|c|}
\hline Signal & Meaning & Consequence \\
\hline & $\begin{array}{l}\text { Blocked } \\
\text { Product quality not achieved } \\
\text { Decisive quality parameter out of } \\
\text { tolerance }\end{array}$ & $\begin{array}{l}\text { Reassign material to lower quality } \\
\text { Stop further processing - use } \\
\text { material as scrap }\end{array}$ \\
\hline & $\begin{array}{l}\text { Temporary blocked } \\
\text { Minor quality or process deviations }\end{array}$ & $\begin{array}{l}\text { Advise the downstream process to } \\
\text { counteract quality deviation } \\
\text { Reassign to material with lower } \\
\text { quality }\end{array}$ \\
\hline & $\begin{array}{l}\text { Approved } \\
\text { All relevant quality parameters within } \\
\text { the limits }\end{array}$ & $\begin{array}{l}\text { Forward the material to the next } \\
\text { internal or external process }\end{array}$ \\
\hline
\end{tabular}

Figure 2: Quality decision matrix 
The integrated solution PQA covers the essential quality aspects of the complete process chain from steelmaking, via hot rolling, cold rolling to final processing.

The main and essential quality aspects are covered and converted into an integrated software solution. The highlights are the following topics:

- Visualization of plant and process conditions related to product quality

- Monitoring of product quality data and interrelations to plant and process status

- Implementation of control actions into automation control loops

- Feedback strategies for operators

- Re-assignment of defective material as an option

Comprehensive process and operational know how and years long experience in quality management is applied to define "steel maker's rules" to support quality decisions. Three kinds of general standards are analyzed:

- Logical rule

- Metallurgical rule

- Empirical rule.

Figure 3 shows in the quality decision rule matrix different basic examples, the description of the problem and the linked proposed action.

\begin{tabular}{clll}
\hline Rule & \multicolumn{1}{c}{ Problem } & \multicolumn{1}{c}{$\begin{array}{c}\text { Examples } \\
\text { Solution }\end{array}$} & \multicolumn{1}{c}{ Benefit } \\
\hline Logical rule & $\begin{array}{l}\text { Thickness in hot strip } \\
\text { mill with up-trend, but } \\
\text { still in tolerance }\end{array}$ & $\begin{array}{l}\text { Feed forward expert advice } \\
\text { to the cold rolling mill: } \\
\text { "Reduce speed for adjust- } \\
\text { ment at rollstand" }\end{array}$ & $\begin{array}{l}\text { Stood within thickness- } \\
\text { tolerance in cold rolling mill }\end{array}$ \\
Metallurgical rule & $\begin{array}{l}\text { Carbon content of the } \\
\text { melt too low }\end{array}$ & $\begin{array}{l}\text { "Lower dewpoint in the gal- } \\
\text { vanizing furnace to avoid fur- } \\
\text { ther decarbonizing" }\end{array}$ & $\begin{array}{l}\text { Melt saved and reprocessing } \\
\text { forder avoided }\end{array}$ \\
Empirical rules & $\begin{array}{l}\text { Too much entrapped } \\
\text { slag at tap }\end{array}$ & $\begin{array}{l}\text { "Lower cleanliness status of } \\
\text { melt and assign to lower ap- } \\
\text { plications" }\end{array}$ & $\begin{array}{l}\text { Early identification of quality } \\
\text { issues and assignment of } \\
\text { melt to maximum appropri- } \\
\text { ate application }\end{array}$ \\
$\begin{array}{c}\text { Pro-active produc- } \\
\text { tion supervision } \\
\text { rule }\end{array}$ & $\begin{array}{l}\text { Roughness with trend in } \\
\text { the skin pass mill, but } \\
\text { decreasing }\end{array}$ & $\begin{array}{l}\text { Early warning "new workrolls } \\
\text { in skin pass mill required" }\end{array}$ & $\begin{array}{l}\text { Trend stopped before dam- } \\
\text { age done }\end{array}$ \\
\hline
\end{tabular}

Figure 3: Quality decision rule matrix 
Figure 4 gives an example how operational know how and experience can help to correct quality non-conformities at later process steps for instance by cutting off deviations before the next process step, such as thickness deviations at the end of the coil.

As an example the methodology for the rules structure is shown in the following table for one specific steel group for one specific process step.



Figure 4: Example for PQA rules for one specific steel group

Taking all gathered quality related process information into consideration including specific process events a quality decision support base is provided.

One strategic core component of the PQA solution is the linking of different information and data to each other by comparing them with actual process data and observation. With reference to the requirements of the TS16949 in chapter 4.1 which is the basis for automotive production in terms of quality supervision and process monitoring, PQA monitors, analyses and compares process data with specifications and defines actions to meet the requirements by using metallurgical and operational experience in actual context.

PQA will be include specific and customized input data:

- Product standards, e.g. DIN, EN, ISO, ASTM et al

- Specific customer specifications: e.g. Mercedes, Toyota, Ford, GM, Exxon, Petrobras

- End use and final application: exposed part

- Metallurgical and operational experience and specific customer know how.

Every decision of the PQA is an individual one which is based on the information which is given by interfaces from order information, specifications and standards 
compared with actual process parameter evaluated and prioritized with contextual metallurgical experience and engineering know how like depicted by the screenshot of figure $\mathbf{5}$ and $\mathbf{6}$. These features make this system an indispensable tool for the successful operation of modern state-of-the-art steel plants.

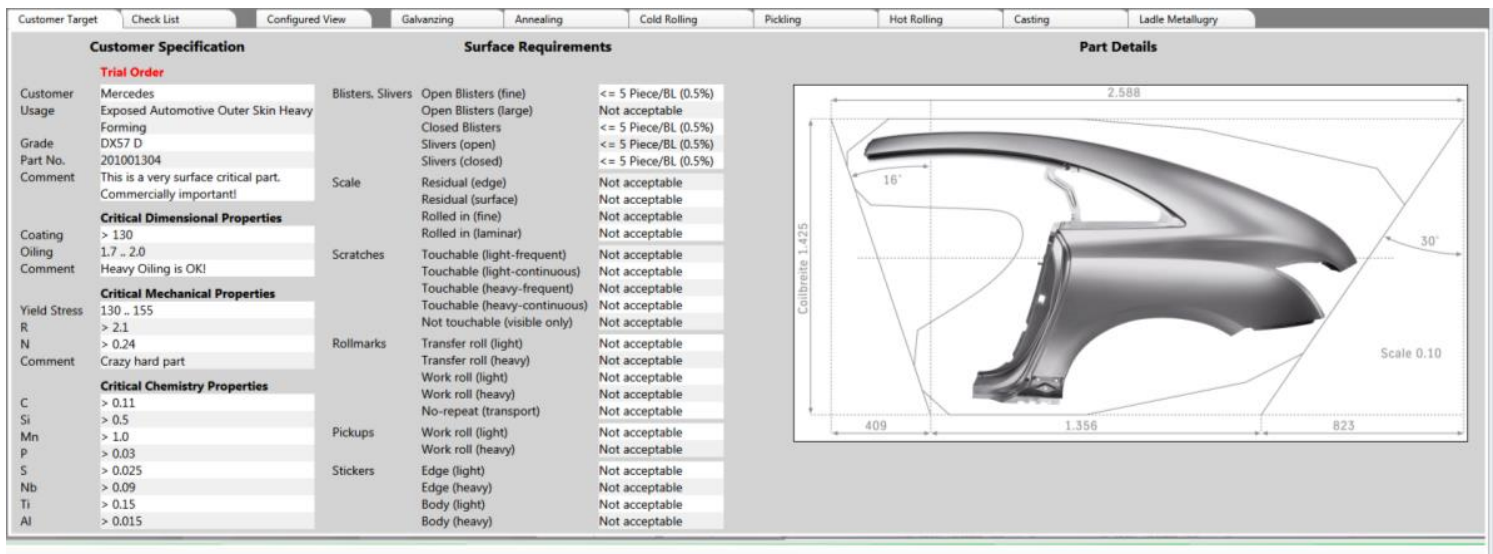

Figure 5: Example of quality information interface: rules and standards

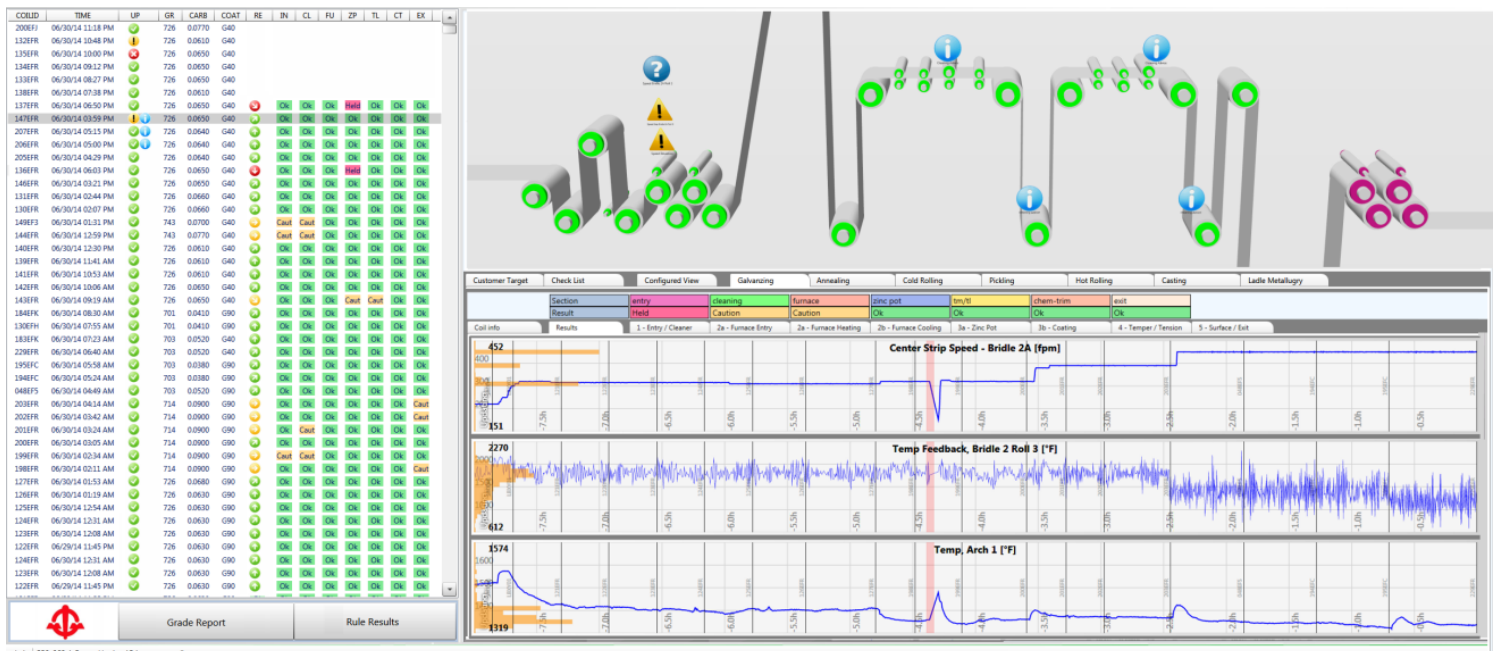

Figure 6: Example of quality information interface: process

\section{QUALITY MONITOR}

Essential part of the PQA system is the Qualitor Monitor. It acts as an integrative interface between the operator or quality manager and the software and data warehouse.

The Quality Monitor provides comprehensive and compiled information; it is a customized information exchange platform.

A reference is shown in figure 7 and comprises, here for reference purposes the following information:

- Coil list and description

- Quality result 
- Applied rule set

- Additional views on details

- Defect maps

- Selected defect, its density and image (if available)

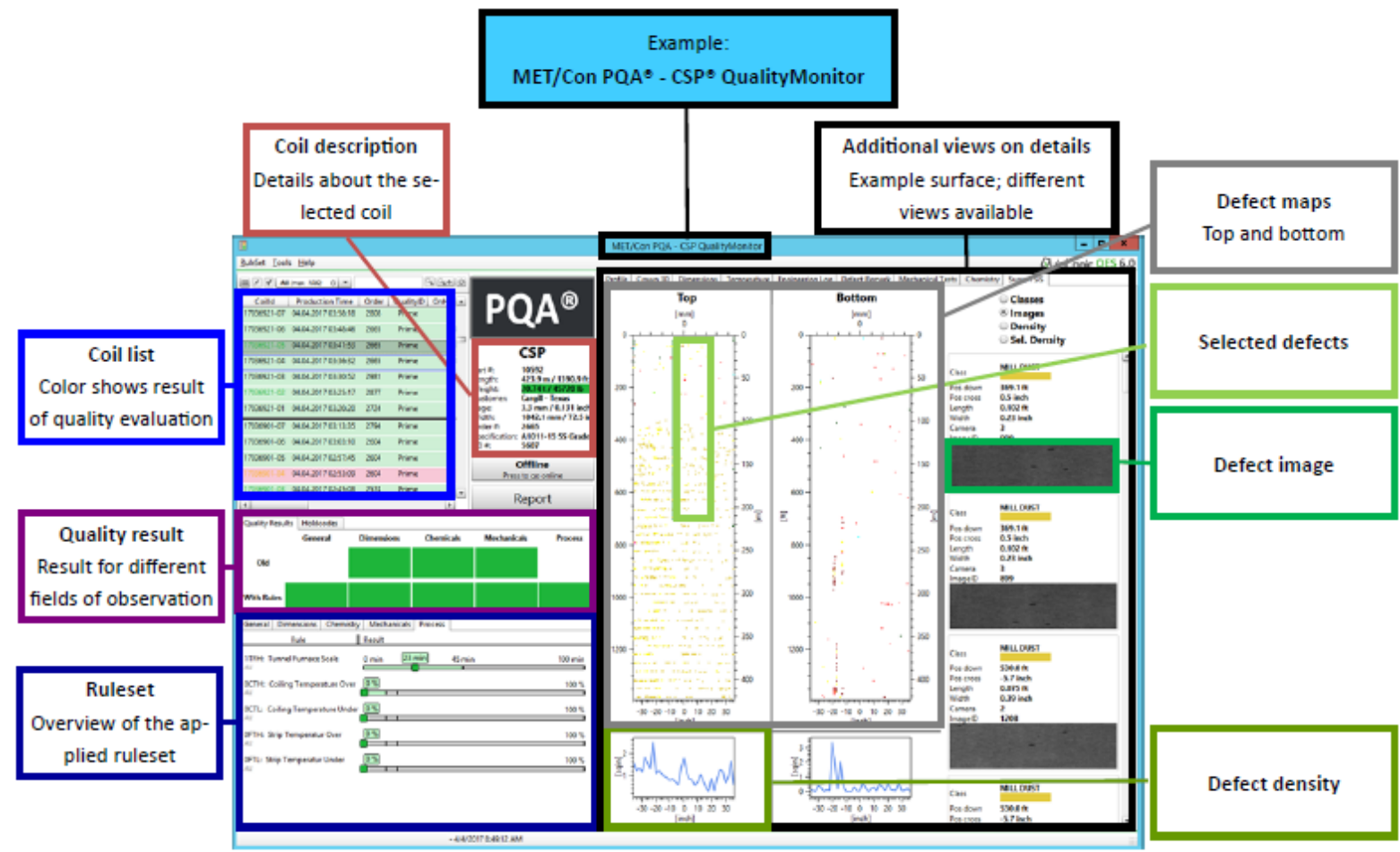

Figure 7: Qualitor Monitor interface to operator

\section{OPERATIONAL STABILITY AND EXCELLENCE}

A PQA solution will become the central tool for product quality analytics and assurance focusing on:

- Stabilizing operational performance

- Improving overall quality management

- Increasing transparency and visibility of quality standards and work on quality optimization

- Enhanced confidence in quality decisions

- Higher stability of operational processes

- Integration of continuous improvement by flexible rule adaption

Following economic advantages and benefits are provided to the operator and user:

- Reduced quality costs by reduction of claim rate and improved delivery performance

- Higher yield of production

- Less rework activities

- Less quality evaluation work by quicker decision making

- Faster quality evaluation and creation of statistics. 


\section{IMPLEMENTATION, CONFIGURATION AND REFERENCES}

Different steel producers globally have realized the necessity for total quality management. Product quality assessment software solutions are implemented at major plants in US, Europe and China including ArcelorMittal, NLMK, Thyssen.

Actually the software package is under implementation at major flat producers in China (BENXI, SHADONG) and in Indonesia at PTKS Krakatau. The solution covers the complete process chain taking steelmaking operation and the continuous casting process into consideration. The hot and cold rolling operation as well as galvanizing and annealing processes are integrated as well.

For Shandong two different hot rolling processes are covered, a conventional hot rolling mill as well as a plate and a steckel mill. The required additional plate processing steps (skin pass rolling and thermal treatment) will be described as well. The PQA system will be the key success factor for Shandong to be established as the prime supplier of state of the art superior products to the market.

The latest and the most modern steel plant in the US, configured as a CSP Mini Mill, at BIG RIVER STEEL successfully commissioned the PQA solution, which is covering the complete process route of EAF and secondary metallurgy, CSP casting, reheating, rolling and coiling, pickling and cold rolling, continuous galvanizing. The superior start-up of operation was directly linked to the support of the PQA system. Within 5 month $90 \%$ plant utilization could be achieved.

Customers have calculated and examined ROI's of time frames in the range of one year, while reducing drastically their quality costs, minimizing scrap and rework and maximizing prime yield. Customer satisfaction is improved in general while improving the delivery performance to end customers and service centers.

The PQA solution has been developed for long steel production and processing (forging, annealing, wire drawing, etc.) and now is implemented as well in a reference project.

\section{CONCLUSION AND SUMMARY}

The PQA has been developed and is implemented in different plants as a quality decision support solution next to existing level 2 and 3 systems, covering the complete process chain from steelmaking till final processing.

The system monitors, documents and safeguards the process and the product quality and can be used as the overall database for further quality, process and production analytics as well.

Based on online process event assessment an early identification of "unsuitable" material can be achieved. The basis for this grading process is a pool of experts based knowledge rules.

The software package provides a real time comprehensive product preview. The system tracks the material over the complete process chain and provides all sensitive coil data at a glance. In case of deviations PQA issues instructions for actions so that potential shortcomings during the production process are recorded. 
PQA is utilized for statistical process and quality evaluations and provides a long term data storage.

User and customer benefits are: Reliable quality, yield increase, cost reduction and satisfied customers.

\section{REFERENCES}

1 [1] Kempken, J; Reifferscheid, M. et. al.: „Integrated Product Improvement by Quality Analysis and Modeling“, Proc. Eur. Cont. Casting Conf. ECCC, Nizza 2005 